\title{
IMIGRANTES AÇORIANOS E SEUS DESCENDENTES NO VALE DO TAQUARI, RIO GRANDE DO SUL: PROCESSO HISTÓRICO ENVOLVENDO MOVIMENTAÇÕES E PRÁTICAS SOCIOCULTURAIS ${ }^{1}$
}

\author{
Luís Fernando da Silva Laroque ${ }^{2}$ \\ Julia Elisabete Barden ${ }^{3}$ \\ Ana Paula Castoldi ${ }^{4}$ \\ Cibele Caroline da Rosa ${ }^{5}$
}

\begin{abstract}
Resumo: O Vale do Taquari é uma região localizada na porção centro leste do estado do Rio Grande do Sul e, historicamente, formada pelas movimentaçôes/migraçóes internas dos grupos étnicos de indígenas, de africanos e de europeus, dentre os quais os açorianos, alemães, italianos e seus descendentes, bem como, mais recentemente, de haitianos e senegaleses. O estudo tem como objetivo analisar a história dos açorianos e de seus descendentes no Vale do Taquari, abordando aspectos relacionados à ocupaçáo territorial e às práticas socioculturais. No Rio Grande do Sul, a presença açoriana iniciou-se a partir de meados do século XVIII e, em fins do referido século, já se encontrava na porçáo sul do Vale do Taquari. No decorrer do século XIX, a relação com a natureza e o território caracterizou-se pela derrubada da floresta, pelo cultivo do trigo, da mandioca e pela criação de animais. Entretanto, com as modificaçóes do traçado da regiáo ao longo do processo histórico e, a partir da metade do século XX, o aumento do número de municípios e áreas urbanas, o cultivo da soja, a criação de porcos e gado leiteiro e, nas últimas décadas, a plantação do eucalipto são
\end{abstract}

1 O trabalho é resultante das pesquisas do projeto "Desenvolvimento Econômico e Sociocultural da Região do Vale do Taquari/RS: determinantes, dinâmicas e implicações", vinculado ao Programa de Pós-Graduação em Ambiente e Desenvolvimento da Univates.

2 Doutor em História. Professor e pesquisador do Programa de Pós-Graduação em Ambiente e Desenvolvimento e do Curso de Graduação em História da Univates. E-mail: 1flaroque@univates.br

3 Doutora em Economia. Professora e pesquisadora do Programa de Pós-Graduação em Ambiente e Desenvolvimento da Univates. E-mail: jbarden@univates.br

4 Ex-bolsista de Iniciação Científica Univates. Graduação em História da Univates. E-mail: anapaulacastoldi13@hotmail.com

5 Bolsista de Iniciação Científica Univates. Graduanda no Curso de História da Univates. E-mail: cibele.rosa@univates.br 
elementos que contribuíram para uma reconfiguração histórica e de práticas socioculturais açorianas e de seus descendentes em áreas rurais do Vale do Taquari.

Palavras-chave: Açorianos e descendentes. Processo histórico. Socioculturalidade. Vale do Taquari.

\title{
AZOREAN IMMIGRANTS AND THEIR DESCENDANTS IN VALE DO TAQUARI, BRAZIL: HISTORICAL PROCESS INVOLVING SOCIOCULTURAL PRACTICES AND MOVEMENTS
}

\begin{abstract}
The Vale do Taquari is a region located in the center-eastern part of the Brazilian state of Rio Grande do Sul and it has been historically formed by internal movements/migrations of different ethnic groups like Indians, Africans, and Europeans, among the latter Azoreans, Germans, Italians and their descendants; recently Haitians and Senegalese have also settled in the region. This paper aims to analyze the history of Azoreans and their descendants in Vale do Taquari approaching aspects related to territorial settlement and sociocultural practices. In Rio Grande do Sul the Azorean presence begun from the Eighteenth century onwards, and in the end of this same century the Azoreans settled in southern Vale do Taquari. During the whole nineteenth century, deforestation, wheat and cassava crops and husbandry featured the relationship with nature and territory. However, due to changes in the sociopolitical layout of the region that occurred along the time and more precisely from the half of the twentieth century onwards, the increase in number of municipalities, urban area, the emergence of soy bean crop, pig farming, dairy cattle and lately the cultivation of eucalyptus, have been shaping the elements that contributed to a historic reconfiguration of Azorean sociocultural practices and their descendants in rural areas of Vale do Taquari.
\end{abstract}

Keywords: Azoreans and descendants. Historic process. Socioculturality. Vale do Taquari.

\section{INTRODUÇÃO}

A Região Vale do Taquari é uma construção territorial e cultural resultante das migrações internas no Rio Grande do Sul e de grupos étnicos como indígenas, africanos e europeus, tais como açorianos, alemães, italianos e seus descendentes e mais recentemente também de haitianos e senegaleses. A região localiza-se na porção centro-leste do Rio Grande do Sul; conta com 36 municípios e está dividida em seis microrregiões que apresentam especificidades econômicas e socioculturais, existindo desde propriedades rurais voltadas ao setor primário até áreas urbanizadas e industrializadas.

A problemática proposta no estudo consiste em apresentar qual o contexto histórico em que se insere a colonização açoriana no Vale do Taquari, quais os espaços territoriais ocupados por parte dos imigrantes açorianos e seus descendentes e que elementos socioculturais deste grupo étnico se fizeram presentes na formação regional do Vale do Taquari. O objetivo do trabalho é analisar a história dos açorianos e seus descendentes no Vale do Taquari, abordando aspectos relacionados à ocupação territorial e às práticas socioculturais. 
O método caracteriza-se por apresentar abordagem qualitativa, com análise de conteúdo com base em aportes teóricos, principalmente de Barth ([1969] 2000), Santos (1996), Corrêa e Bublitz (2006) e Nordari (2009). Consiste no levantamento de dados coletados na revisão bibliográfica sobre a imigração açoriana do Rio Grande do Sul e do Vale do Taquari, nos diários de campo elaborados e nas entrevistas orais realizadas com produtores rurais descendentes de açorianos localizados nas microrregiões centro e sul da região do Vale do Taquari. Na pesquisa bibliográfica, realizou-se o levantamento inicial, catalogação e análise dos dados sobre a imigração açoriana em territórios do Rio Grande do Sul e do Vale do Taquari. Os diários foram elaborados durante a pesquisa de campo durante os anos 2013, 2014, 2015 e 2016, inseridas em um projeto de pesquisa da Univates, que aborda aspectos econômicos e socioculturais de grupos étnicos de açorianos, alemães, italianos no Vale do Taquari e produtores rurais descendentes, cujo levantamento já possui cinquenta e seis descendentes das referidas etnias. Selecionou-se, para este estudo, uma amostra de seis entrevistas semiestruturadas e diários de campo, os quais, no período em questão, foram realizados com produtores rurais descendentes de açorianos. Nas entrevistas, utilizou-se o Termo de Consentimento Livre Esclarecido (TCLE), assegurando a não identificação dos produtores rurais que, neste estudo, são denominados E5, E6, E19, E22, E23 e E44.

\section{PRESENÇA E MOVIMENTAÇÓES DE GRUPOS ÉTNICOS AÇORIANOS EM TERRITÓRIOS DO RIO GRANDE DO SUL E DO VALE DO TAQUARI}

Relativamente à presença e movimentações pelo território de europeus no processo colonizatório do Rio Grande do Sul e do Vale do Taquari, é preciso considerar principalmente os grupos étnicos de açorianos, alemães e italianos, os quais estabeleceram-se em pequenas propriedades (AHLERT; GEDOZ, 2001). Particularmente no vale do rio Taquari, os açorianos, conforme Carvalho (2002), chegaram à região em fins do século XVIII e estabeleceram-se na porção sul do território, enquanto os alemães, italianos e seus descendentes, que somente instalaram-se na região a partir de meados do século XIX, respectivamente, ocuparam a porção central do território e áreas ao norte do mesmo, conforme mapa a seguir (FIGURA 1). 
Figura 1: Mapa da Colonização do Vale do Taquari

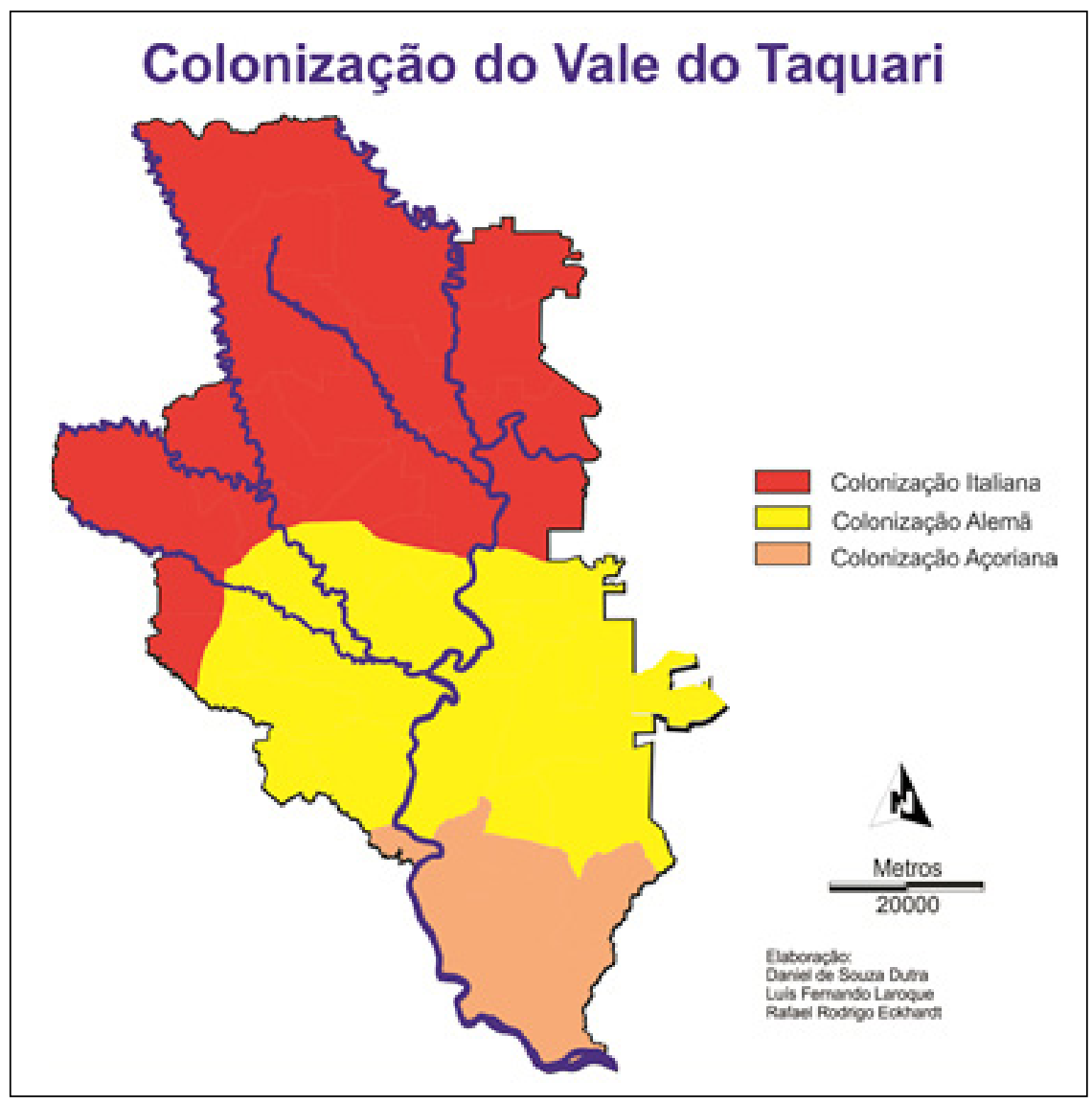

Fonte: Organização do autor.

No ano de 1747, segundo Meneses (2004), documentos apresentam uma relação de 7.971 pessoas dos Açores, provenientes das ilhas São Miguel, Terceira, Graciosa, São Jorge, Faial e Pico, que se alistam para o Brasil. O destino de parte desses açorianos foi a Província de São Pedro do Rio Grande do Sul, pois, conforme Pesavento (1992), os casais d'El Rey foram alistados para povoar o território das Missões. Entretanto, devido à Guerra Guaranítica (1754-1756) conflito entre indígenas Guarani que apresentava posição contrária sobre a troca de jurisdição do território dos Sete Povos das Missões pelo território da Colônia de Sacramento acordado entre Portugal e Espanha - impediu que os casais açorianos se estabelecessem na área prevista. Neste sentido, temos:

Chegados na metade do século XVIII com o fim de irem povoar as Missões, que pelo Tratado de Madrid passariam a ser possessão portuguesa [...], os casais "d'El Rey", uma vez chegados, espalharam-se irregularmente, ficando quase 20 anos sem receber as terras prometidas. Somente no Governo de José Marcelino de Figueiredo (1764-80) é que foram cumpridas as promessas da Coroa, concedendo-lhes uma data (372 hectares), a fim de que começassem, 
através de uma agricultura com base em mão-de-obra familiar, a suprir as necessidades de subsistência da colônia (PESAVENTO, 1992, p. 16).

Em 19 de novembro de 1752, o Coronel Cristóvão Pereira de Abreu, seguindo as instruções de Gomes Freire, Governador do Rio de Janeiro, instalou nos Campos de Viamão, trazidos da Vila de Rio Grande, "um continente de casais açorianos, os quais aguardariam no Porto de Ornelas (atual Porto Alegre) e sua transferência para as Missões (GRAEBIN, 2004, p. 205). Contudo, em decorrência do conflito nas Missões e a falta de demarcação do território prometido, segundo Borges Fortes (1978) e Wiederspahn (1979), os açorianos se dispersaram por áreas do Vale do Jacuí e fundaram diversos povoados como Rio Pardo, Santo Amaro, Triunfo, Taquari e Santo Antônio da Patrulha.

Portanto, é neste contexto de movimentação pelo território que mais precisamente em 1760, os açorianos chegaram à Freguesia de São José do Taquari. A fundação desta localidade deu-se em 1764, com a instalação de 14 casais e, em 1770, já se encontravam no local mais de 60 famílias de açorianos. Sobre isto temos:

A formação de pequenas povoações garantiu, entre várias outras coisas, o adensamento populacional de um vazio demográfico, no qual as primeiras doações de sesmarias próximas ao rio Jacuí não resolveram o problema. Neste sentido foram fundados os povoamentos de São José de Taquari e Santo Amaro. Estas receberam casais açorianos na década de 1760, havendo 60 deles no vale em 1770 (CHRISTILINO, 2004, p. 24).

Dependendo do espaço geográfico em que os açorianos se encontravam, Graebin (2006 e 2014) salienta que estes se relacionavam com a terra de diferentes maneiras, cultivando trigo, abóbora, feijão, couve, cebola, mandioca, batata, milho, nabo, melancia, cana-de-açúcar, cevada, alpiste, aveia, ervilha, centeio, assim como plantando árvores de espinho, como laranjeiras, limoeiros e bergamotas, além de pessegueiros, bananeiras, amoreiras, pereiras e também a criação de animais para consumo doméstico como é o caso de galinhas, patos e bovinos. Algumas famílias possuíam moinho para o fabrico da farinha de trigo e a atafona, para a produção da farinha de mandioca. Vale salientar, de acordo com Graebein (2004, p. 160), que "os casais de agricultores tiveram de derrubar a mata e construir suas casas, apropriando-se da natureza".

Os açorianos, instalados tanto em São José do Taquari como em Santo Amaro, dedicaram-se ao cultivo de hortaliças e do trigo como alternativa para a obtenção da sustentabilidade econômica. As localidades em questão foram propícias para a introdução de hortaliças e frutas de origem europeia e africana o que, segundo Correa e Bublitz (2006), caracteriza como mais uma prática da colonização açoriana, mas que também acarretaram forte impacto na destruição da mata ciliar local. Ainda sobre as formas de culturas da comunidade açoriana no vale, os autores enfatizam a presença do trigo como sendo a "primeira lavoura especializada" (CORREA; BUBLITZ, 2006, p.50). Em termos hidrográficos, o rio Taquari, apresentava-se como o principal meio de deslocamento e escoamento da produção. 
Segundo referido, na região conhecida, na atualidade, como Vale do Taquari, a ocupação deu-se em fins do século XVIII com a chegada de açorianos "[...] originários de Taquari, que aos poucos foram tomando posse de fazendas localizadas no lado sul do município" (JUNG, 2001, p.16). Corroborando a questão, o estudo demográfico de Scott e Berute (2014, p. 124), indica que, na igreja de Taquari “[...] entre 1767 (ano de sua instalação) e 1800, foram registrados os 275 assentos de casamento"6.

Essas famílias, instaladas inicialmente em São José do Taquari, contribuíram, no decorrer dos anos, para o reforço étnico açoriano e a continuidade de elementos culturais dos ilhéus lusitanos. Segundo Silva (2009), algumas cidades do Vale do Taquari, como, por exemplo, Paverama e Taquari, ainda guardam forte influência

6 Dos casamentos registrados na Freguesia de São José do Taquari, entre 1767 e 1800 , em que ao menos um dos conjugues é natural de Ilhas dos Açores, apontam-se quarẹta e quatro matrimônios que são: Matheus Teyxeyra Fagundes (Ilha São Jorge) com Francisca Maria de Bettancure (Laguna), Lourenço de Quadros (Illha Graciosa).com Esperança Maria do Epírito Santo (Santa Catarina), Francisco Joze (Ilha Faial) com Maria de Jezus (Ilha Terceira), Manoel Pereyra da Luz (Ilha de São Jorge) com Ignacia Maria de Jezus (N. Sra. da Conceição de Viamão), Francisco de Souza (Ilha de Sâo Jorge) com Ricarda Maria (N. Sra. da Conceição de Viamão), Antonio Dornellas (Ilha Terceira) com Maria do Rozario (N. Sra. da Conceição de Viamão), Antonio Dias Gonçalves (Ilha Faial) com Maria do Nascimento (Rio Grande), Manoel Ignacio ( Ilha de São Jorge) com Maria Tereza do Espírito Santo (N. Sra. da Conceição de Viamão), Manoel da Sylva (Ilha Faial) com Antonia Maria de Bettancur (N. Sra da Conceição de Viamão), Paulo Ferreyra (Ilha de São Jorge) com Brizida Maria de Jezuz (Freguesia da Conceição de Viamão), Manoel Machado de Souza (Ilha de São Jorge) com Escolastica do Rozando (Freguesia do Sr. Bom Jesus do Triunfo), Antonio de Souza (Itha São Jorge) com Anna Maria (localidade não informada), Antonio Francisco Silveira (Ilha do Faial) com Getrudes Maria do Rozario (Ilha Terceira), João Francisco de Medeiros Braga (Ilha de São Miguel) com Maria Magdalena de Oliveira (N. Sra. da Conceição de Viamão), Andre Machado Alz (Ilha Terceira) com Ana Maria de San Francisco (Freguesia de Sta Rita do Rio de Janeiro), Lourenço Machado (Ilha de São Jorge) com Luzia Ignacia da Conceissam (N. Sra. da Conceição de Viamão), Pedro Joze de Mendonza (Ilha Graciosa) com Francisca da Silva (Freguesia do Sr. Bom Jesus do Triunfo), Andre Machado (Ilha de São Jorge) com Ana do Rozario (Rio Grande), Joze Silveira de Castro (llha do Faial) com Anna Maria (N. Sra. da Conceição de Viamão), Francisco Gomes Parrẹira (Castro Avelães, Bispado de Bragança) com Maria Ignacia Faria de Lacerda (Ilha do Faial), Antonio da Costa Machado (Ilha Terceira) com Brizida Maria (Rio Pardo), Jacinto Rodrigues Jaques (Ilha do Faial) com Anna Maria (Freguesia do Sr. Bom Jesus do Triunfo), Joam Rodrigues Vila do Conde, Arcebispado de Praga) com Maria Anna de Jesus (Ilha do Pico), Manoel Joze (Ilha do Faial) com Josefa Tereza (Ilha do Faial), Joze de Souza Murer (Ilha do São Jorge) com Roza Maria de Jezus (Rio Grande), Joze Machado de Souza (Ilha de São Jorge) com Joana Maria do Rozario (Freguesia do Sr. Bom Jesus do Triunfo), Manoel Joze (Freguesia do Sr. Bom Jesus do Triunfo) com Vicência Maria (Illha do Faial), Mathias da Costa Leyre (Ilha de Santa Maria) com Marya Sylveyra (Ilha do Faial), Joze de Souza Dias do Nascimento (Ilha do Faial) com Roza Maria (Ilha de São Jorge), Felipe de Souza Pedrozo (Ilha de São Jorge) com Maria Thereza de Jesus (Freguesia do Sr. Bom Jesus do Triunfo), Manoel Silveira Dutra (Ilha do Faial) com Ritta Maria (Freguesia do Sr. Bom Jesus do Triunfo), Joam Pedro (Ilha de Santa Maria) com Anna Maria (Ilha de Santa Catarina,Brasil), Guabriel de Souza Santiago (Freguesia do Sr. Bom Jesus do Triunfo) com Roza Maria de Jezus (Ilha do Faial), Francisco Antonio de Vargas (Rio Pardo) com Mariana Roza de Jezus (Freguesia do Sr. Bom Jesus do Triunfo), Leandro Pereira da Silva (Ilha do Faial) com Perpetua Roza de Jezus (Freguesia do Sr. Bom Jesus do Triunfo), Juam Vieira do Amaral (Ilha do Pico) com Anna Maria (localidade não informada), João Teixeira Machado (Ilha de São Jorge) com Emerencianna Maria do Rozario (Freguesia de São José do Taquari), Joao Machado Atveres (Ilha de São Jorge) com Izabel Francisca de Bitancurt (Ilha de São Jorge), Francisco Antonio de Souza (Porto Alegre da N. Sra da Madre de Deus) com Bibiana Maria (Ilha do Faial), Francisco Correa Serafana (Ilha do Faial) com Antonia Leite de Oliveira (N. Sra. da Conceição de Viamão), Joaquim Joze de Andrade (Ilha Terceira) com Clara Maria de Jezus (Freguesia de São José do Taquari), Manoel Dutra Pareia (Ilha do Pico) com Escolastica do Rozario (Freguesia do Sr. Bom Jesus do Triunfo), Manoel Garcia da Roza (Freguesia de São José de Taquari) com Rozaura Maria da Conceição (Ilha do Faial) e Miguel Ignacio da Silva (Ilha Terceira) com Francisca de Jezus (Freguesia de São José dr Taquari) (NACAOB - Banco de dados da Freguesia de São José de Taquari, in: SCOTT'; BERUTE, 2014). 
cultural açoriana, principalmente na religião, arquitetura e gastronomia, como é possível observar nos ternos de reis, fachadas de casas e nas comidas típicas.

Vale salientar que uma expressiva parte do espaço que denominamos Vale do Taquari, conforme Vedoy (2015), foi colonizada por uma elite fundiária estabelecida nos Campos de Viamão, cuja jurisdição, no século XVIII, estendia-se sobre os territórios dos rios do Sinos, Caí, Gravataí e Taquari, onde muitos portugueses, dentre os quais açorianos de posses, haviam recebido sesmarias da Coroa portuguesa. Na primeira metade do século XIX, essas sesmarias vão dar origem a fazendas, como é o caso da Fazenda dos Conventos, Fazenda da Estrela, Fazenda São Gabriel, entre outras, respectivamente instalas em áreas em que atualmente localizam-se municípios como Lajeado, Estrela e Cruzeiro do Sul (VEDOY, 2015). De acordo com Christillino (2004), as principais fontes econômicas eram o trigo, a produção de madeira, extração de erva mate e de pedras, estas principalmente encontradas às margens do rio Taquari. Portanto, o modo de produção no território que conhecemos como Vale do Taquari estava em consonância com o contexto da Província de São Pedro do Rio Grande do Sul, visto que, "no total, mais de 45\% da população era cativa, um percentual muito elevado, semelhante ao encontrado nas zonas mineradoras ou de plantation e não muito adequado a uma região voltada ao mercado interno" (KUHN, 2004, p.51).

Entretanto, com a Lei de Terra de 1850 e, principalmente, pela crise que estas fazendas já vinham enfrentando devido à política governamental e à Guerra Farroupilha, alguns proprietários passam a vender estas fazendas para Companhias Colonizadoras de particulares que dividem os territórios em áreas menores - as colônias - as quais são comercializadas para a instalação principalmente de imigrantes alemães, italianos e seus descendentes. Um destes negociantes de terra, segundo Ahlert e Gedoz (2001), é Antonio Fialho de Vargas, que mantinha em seu poder áreas do Vale do Taquari, no atual município de Muçum, Arroio do Meio e Estrela. Temos ainda, na obra de Karam (1992), que Fialho mantinha em sua posse terras da fazenda dos Pinheiros, atual município de Dois Lajeados.

Na segunda metade do século XIX, a região do Vale do Taquari passou por diversas transformações na sua divisão político-administrativa. Foi criado, em 1849, o município de Taquari, o primeiro que compôs a atual região do Vale do Taquari, após seu desmembramento de Triunfo. Posteriormente, em 1876, foi criado o município de Estrela e, no ano de 1892, a Vila Lajeado.

Neste contexto, constatamos que as famílias de imigrantes açorianos e de seus descendentes, grosso modo, desde a última década do século XVIII, embora movimentando-se pelo território, permaneceram em territórios das Microrregiões Centro e Sul do Vale (SILVA, 2006). Na década de 1940, segundo Barden e Ahlert (2003), ocorreram deslocamentos populacionais intra-regionais como interregionais, possivelmente devido ao esgotamento do solo e também pelo declínio das atividades de produção.

Segundo Santos (1996, p.18), em cada momento histórico, “[...] o espaço reproduz a totalidade social, na medida em que essas transformações são 
determinadas por necessidades sociais, econômicas e políticas". Assim, mas refutando a ideia de um espaço determinista, percebe-se que a formação do Vale do Taquari está intimamente ligada às socioculturalidades dos povos que nele se instalaram, dentre estes os açorianos, os quais também contribuíram para a transformação do território por meio de suas ações e movimentações.

\section{O ESPAÇO TERRITORIAL DENOMINADO REGIÁO DO VALE DO TAQUARI E AS FRONTEIRAS GEOGRÁFICAS, ÉTNICAS E CULTURAIS}

Segundo Aguiar et al. (2009), o território conhecido como Vale do Taquari, Rio Grande do Sul, na década de 1970, era denominado microrregião Colonial do Alto Taquari e a Colonial do Baixo Taquari ${ }^{8}$. Com a Constituição Federal de 1988, foi determinado que os estados criassem suas próprias divisões regionais. No Rio Grande do Sul, o governo, em 1994, criou os Conselhos Regionais de Desenvolvimento (COREDEs), contudo, no Vale do Taquari, o Conselho de Desenvolvimento do Vale do Taquari (CODEVAT), criado desde dezembro de 1991, já havia revisto sua divisão regional. Neste sentido, temos:

[...] numa clara revisão e unificação da ideia de região que as instituições possuíam: não havia mais espaço para se tratar a região como alto e baixo vale, por exemplo. $\mathrm{O}$ vale do Taquari era um só. Identificado com um território com a formação social e econômica dada pela história ao longo da bacia do rio Taquari (AGUIAR et al., 2009, p. 97).

O Conselho de Desenvolvimento do Vale do Taquari (CODEVAT) é um dos 26 Conselhos Regionais de Desenvolvimento (COREDEs), sobre o qual nos baseamos para a elaboração do mapa (FIGURA 2), onde podemos identificar as seis microrregiões em que o Vale do Taquari se encontra dividido. Esta divisão político-territorial do vale, envolvendo as fronteiras geográficas das microrregiões, se aproxima do que Helena Callai (2000) denomina construções históricas geopolíticas, mas, em nosso ponto de vista, não necessariamente corresponde às fronteiras culturais constituídas pelos grupos étnicos de açorianos, alemães, italianos e seus descendentes que ocuparam a região.

7 Formado pelos municípios de Anta Gorda, Arvorezinha, Casca, David Canabarro, Fontoura Xavier, Guaporé, Ilópolis, Nova Araçá, Nova Bassano, Nova Prata, Paraí, Putinga e Serafina Corrêa. Entre estas, Guaporé, situada já na serra (encosta superior do Nordeste), era então a cidade mais polarizada dessa microrregião.

8 Composto pelos municípios de Arroio do Meio, Bom Retiro do Sul, Cruzeiro do Sul, Encantado, Estrela, Lajeado, Muçum, Nova Bréscia e Roca Sales. 
Figura 2: Mapa das Microrregiões no Vale do Taquari

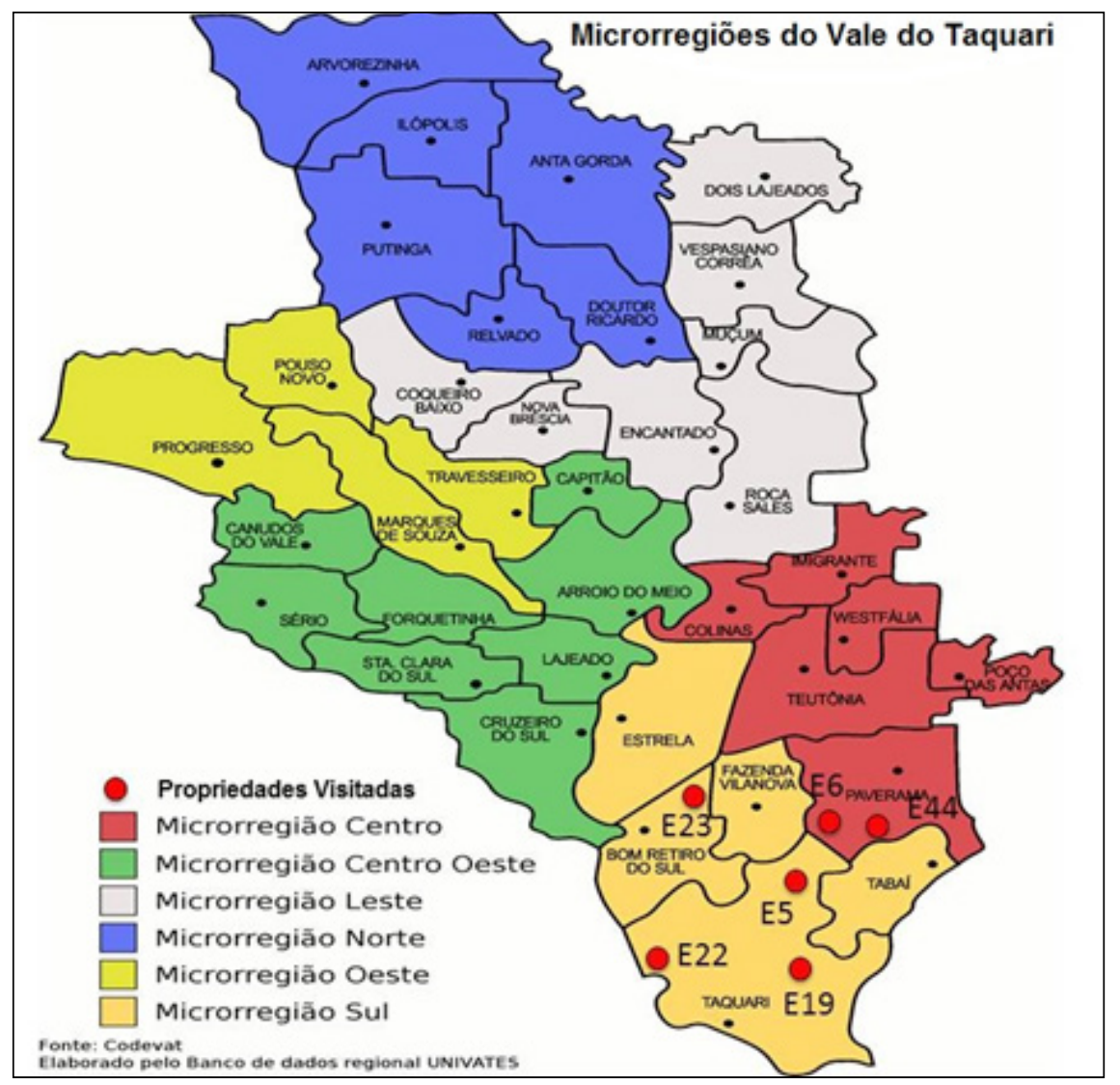

Fonte: Organização do autor.

Vale salientar que, neste estudo, entende-se fronteira geográfica como elemento que faz parte do processo de construção socioespacial humana. Conforme Ferrari (2014), o Estado Moderno passou a associar o limite territorial de uma nação e de sua soberania, situação que também podemos identificar no território que constitui a região Vale do Taquari. Ou seja, "[...] o território demarcado passa a ser considerado a matriz da legitimidade espacial do direito do Estado constituído por normas jurídicas válidas em seu interior [...]” (FERRARI, 2014, p. 12).

Tratando-se de fronteira cultural, utilizamos esta categoria a partir do estudo de Barth ([1969], 2000) e de uma entrevista concedida por ele, em novembro de 1995, que se encontra na obra "O guru, o iniciador e outras variações antropológicas" (2000), organizada por ele e Tomke Lask. Sobre a fronteira cultural, tem-se:

Isso torna possível compreender uma última forma de manutenção de fronteiras étnicas através da qual unidades e fronteiras culturais persistem. A manutenção de fronteiras étnicas implica também a existência de situações de contato social entre pessoas de diferentes culturas: os grupos étnicos só se mantêm como unidades significativas se acarretam diferenças marcantes 
no comportamento, ou seja, diferenças culturais persistentes. No entanto, havendo interação entre pessoas de diferentes culturas, seria esperado que essas diferenças se reduzissem, uma vez que a interação tanto requer como gera certa congruência de códigos e valores - em outras palavras, uma similaridade ou comunidade cultural [...]. Assim, a persistência de grupos étnicos em contato implica não apenas a existência de critérios e sinais de identificação, mas também uma estruturação das interações que permita a persistência de diferenças culturais (BARTH, 2000, p.34-35, grifo dos autores).

Portanto, a fronteira cultural é entendida neste trabalho como uma dinâmica social em que culturas entram em contato, e os elementos postos na ação passam a ser atualizados, interpretados ou reinterpretados segundo os parâmetros de cada um dos grupos envolvidos. Isto é o que percebemos com os açorianos e seus descendentes no Vale do Taquari, principalmente nas relações estabelecidas com os demais grupos étnicos que estabeleceram contato, tais como os alemães, os italianos e seus descendentes.

Considerando o espaço territorial do Vale do Taquari como uma construção histórica, percebe-se que os limites das fronteiras geográficas ou territoriais também passam por transformações. No passado, por exemplo, tomando a acepção de Mesquita (1994) sobre limite ${ }^{9}$ e divisa ${ }^{10}$, temos como divisor fronteiriço de cunho político administrativo o alto e o baixo rio Taquari ${ }^{11}$, mas, nas últimas décadas, com o CODEVAT, conforme já nos referimos, este divisor passa a ser a microrregião norte, microrregião sul, microrregião leste, microrregião oeste, microrregião centro e microrregião centro-oeste.

É relevante salientar que mesmo com as alterações dos limites e divisas envolvendo as reconfigurações das fronteiras geográficas ou territoriais no Vale do Taquari, as movimentações entre o alto e o baixo Taquari e/ou migrações interregionais pelos imigrantes açorianos, alemães, italianos e seus descendentes, não deixaram de ocorrer e significar algum tipo de isolamento geográfico, ou mesmo, descontinuidade cultural entre estes grupos étnicos.

9 Mesquita (1994, p.70) informa que “[...] o 'limite’ é reconhecido como linha, e não pode ser habitado, portanto; ao contrário da 'fronteira' que, ocupando uma faixa, constitui uma zona, muitas vezes bastante povoada, onde os habitantes de estados vizinhos podem desenvolver intenso intercambio".

10 Divisa o aspecto visível do limite, os quais podem apoiar-se em acidentes naturais, como cursos d'água, cristas montanhosas, ou mesmo, coordenadas geográficas.

11 Sobre a denominação alto e baixo Taquari, temos que até “[...] aproximadamente 1990, os vale-taquarienses se (re)conheciam como pertencentes à região do Alto Taquari, conforme evidenciam as próprias denominações conferidas à Instituição [...]. Havia, inclusive, duas denominações: Alto Taquari e Baixo Taquari, embora tal divisão jamais tivesse constatado no mapa político-administrativo do Rio Grande do Sul. A partir da criação dos Conselhos Regionais de Desenvolvimento - COREDES [1994], mais especificamente com a criação do Conselho de Desenvolvimento do Vale do Taquari - CODEVAT [um dos COREDES], a região passou a figurar no mapa do Rio Grande do Sul como Vale do Taquari” (FALEIRO, 2009, p. 15). 
[...] torna-se claro que as fronteiras étnicas permanecem apesar do fluxo de pessoas que as atravessam. Em outras palavras, as distinções entre categorias étnicas não dependem da ausência de mobilidade, contatos e informação, mas implicam efetivamente em processo de exclusão e de incorporação, através do quais, apesar das mudanças de participação e pertencimento ao longo das histórias de vida individuais, estas distinções são mantidas. [...] há relações sociais estáveis, persistentes e frequentemente vitais que não apenas atravessam essas fronteiras como também, muitas vezes, baseiam-se precisamente na existência de status étnicos dicotomizados (BARTH, [1969], 2000, p. 26).

Ou seja, no caso dos açorianos e dos produtores rurais descendentes das microrregiões centro e sul que estudamos, mesmo com a interação das unidades étnicas ao longo da história, percebe-se que este grupo não perdeu seus elementos culturais, e essas interações serviram justamente para o fortalecimento do sentimento de pertença.

\section{PRÁTICAS SOCIOCULTURAIS DE IMIGRANTES AÇORIANOS E DE SEUS DESCENTES EM ÁREAS RURAIS DO VALE DO TAQUARI}

Tratando-se das práticas culturais, o produtor rural entrevistado E5 (21/06/2013), descendente de açoriano da Microrregião Sul, relata que, no passado, toda a família envolvia-se no cultivo das roças de mandioca e no preparo da farinha por meio de atividades na atafona. Sobre isso, temos:

Atafona é, como eu te disse: tem que buscar a mandioca, plantar a mandioca, arrancar a mandioca, botar na carroça, trazer e largar. Tinha uma raspadeira, aí não funcionava porque não tinha água, aí nós tínhamos que raspar à mão, assim ó, a mandioca, aí raspava a mandioca, largava dentro de um cocho, aquele cocho botava no rodízio, o rodízio moía aquela mandioca, saía a massa! Da massa a gente agarrava e botava na prensa. $\mathrm{Na}$ prensa, a gente tocava a prensa até secar aquela massa. Quando aquela massa estava seca, aí mexia com a mão assim, tinha uma coisa que a gente agarrava assim, né, e botava dentro do tacho do fogo. Aí era um tacho, como daqui lá assim, bem grandão, e aí tinha umas muletas dentro, que fazia assim, mexia o tacho né, ia andando em roda com aquela farinha assim, né, com a massa, até virar farinha de mandioca (E5, 21/06/2013, p. 10).

O trabalho era feito diariamente, mesmo em fins de semana e nos dias de comemorações, quando a comunidade se reunia para preparar as festas religiosas. $\mathrm{Na}$ atualidade, com base nos relatos, é possível perceber que as festas em comemoração aos Santos, como, por exemplo, Nossa Senhora da Conceição e São José, continuam, mas são menores, já que a comunidade descendente de açorianos que permanece na área rural da microrregião em questão também diminui, do ponto de vista demográfico, considerando o fato de que muitos jovens se mudaram para áreas urbanas.

Destacam-se ainda, durante os períodos de colheita, os chamados pixuruns, nos quais, toda a vizinhança se reunia para auxiliar na colheita dos alimentos. Neste sentido, o entrevistado E19 (25/02/2014), Microrregião Sul, informa: 
É, a genti marcava, a genti juntava as vezes, báh má a mandioca vô tê que capiná tudo, i capinava né, ahã mandioca descascava ela lá i logo ia limpá, ou todo mundo ia fazê lá aquele pixuru, fazia os pixuru, fazia umas bóia lá na moita lá, i capinavam, i era bem legal, báh, só via aquela pueira ali, i tinha ainda os versinhu qui eles cantavam [...] (E19, 25/02/2014, p. 2).

O entrevistado E23 (09/01/2015), no que diz respeito a esta mesma prática relata:

Pixurúns faziam, isso o pai dele fazia, o meu também, aí, assim, os vizinhos se reuniam, hoje um, um outro, um outro, e capinavam, cantavam, tinha as cantigas mesmo que esses dia eu tava olhando no nordeste eles cantam também, só que lá no nordeste eles cantam com pá de cisco.

[...] Aí eles cantavam, eles cantavam, aí depois na hora do almoço tinha que tê uma comida diferente, um churrasco, um leitão assado, leitão assado no forno. Aquele forno feito de tijolo lá na rua. Eles assavam aqueles leitão, levava dois dia assando pra até o dia do pichurú chegá. Ontem eles começavam pra amanhã tê o pichurú (E23, 09/01/2015, p. 18).

Tratando-se de práticas culturais envolvendo a culinária, o entrevistado E44 (28/01/2016), Microrregião Centro, descreve como grande presença na mesa açoriana a mandioca, que se transformava em farinha por meio da atafona. Também eram feitos o polvilho e o beiju, chamado em outras regiões de tapioca, além do cuscuz, feito com a massa da mandioca a vapor.

Corroborando as práticas que envolvem a culinária, o entrevistado E19 (25/02/2014) informa o seguinte:

Qui nem, quandu a genti si criou, era secado fora a farinha, fazê u polvilho, aí a minha mãe secava u polvilho prá fazê a farinha sacos e sacos, inchia a carroça, saía as veiz duas hora da madrugada i ia até num atacado prá comprá aquelis mantimentu, i prá comprá... que era di querosene, é o saco de farinha, a querosene e o sal era o que ficava do lado da casa, aí depois vinha a farinha de trigo, i o açúcar né [...]. (E19, 25/02/2014, p. 12).

Somados ao cultivo do milho e à produção do leite, há alguns dos produtores rurais entrevistados que plantam batata, feijão e pepino, que são continuidade de práticas das gerações passadas. Somente o pepino foi incluído há poucos anos, com incentivo da prefeitura de Taquari. Segundo o produtor E22 (22/12/2014), Microrregião Centro, ele prefere manter uma diversidade de cultivos, ao invés de dedicar-se a uma só atividade, já que, quando uma é desvalorizada, ele poder contar com outras para sua sustentabilidade econômica.

É quase a mesma coisa, porque a cultura aqui é feijão e milho, agora a gente planta pepino, batata, o que mais, feijão, di tudo um pouco né. [...] O leite, o meu ganha pão é o leite (E22, 22/12/2014, p. 3).

O referido produtor também destaca sua preocupação com relação ao futuro do meio rural, considerando que os jovens não mais querem permanecer no campo. Em sua narrativa reflete sobre a alimentação da população urbana daqui alguns anos, caso não mais houver produtores rurais. Informa que seus filhos, bem como 
os de outros produtores rurais que conhece não querem mais ficar no meio rural e mudaram-se para os centros urbanos. Dentre os motivos para isto reclama da falta de incentivo governamental, falta de acesso ao lazer, baixa lucratividade, entre outros. Sobre os jovens, ele destaca que é "[...] cada vez mais indo pra cidadi. I divia sê talvez ao contrário, sei lá, não digo contrário, mas tem que tê mais incentivo oras também né, pra podê ficá" (E22, 22/12/2014, p. 7).

Referente às práticas envolvendo o meio ambiente E5 (21/06/2013, p. 38), informa em sua narrativa que "Tinha esse mato comum lá, que eu te falei, mas isso era mato que... aí depois o pai foi derrubando, foi fazendo roça, porque naquele tempo eles não proibiam. Não tinha esse negócio do meio ambiente, e ele foi derrubando, plantava uma roça de feijão, milho ali, aí a terra era muito boa [...]”. Considerando essas questões, a partir do enfoque ambiental, temos:

\begin{abstract}
A agricultura, o comércio e a indústria, especialmente as serrarias e a vinicultura, devem ser entendidas, para além de seu viés econômico, como fatores de modelagem da paisagem colonial, que se traduziu em termos religiosos a partir do domínio civilizatório imposto pelos imigrantes sobre o meio. [...] (CORREA; BUBLITZ, 2006, p. 76).
\end{abstract}

A industrialização e a modernização das atividades também aparecem na narrativa de outro produtor, E6 (12/07/2013), Microrregião Centro. Segundo seu relato, a área rural perdeu mão de obra e, nas últimas quatro décadas, os produtores precisaram se adequar às necessidades do mercado, transformadas com a inserção de agrotóxicos nas lavouras, que multiplicaram a produção, mas acarretaram a desvalorização dos produtos e das práticas tradicionais de cultivo. E6 (12/07/2013), lembra que, na década de 1970, plantava soja, mas depois passou para a produção do leite e a criação de suíno, atividades que deram continuidade na década de 1980. Entretanto, na década de 1990, abandonou a criação do suíno, bem como o cultivo da soja, que não era mais viável, mantendo apenas o leite e dedicando-se também à criação de frango.

Sobre suas práticas de trabalho, o referido produtor complementa, afirmando: "Quando larguei [soja] era tudo manual, tudo no boi, quando começou isso [agrotóxicos] a soja desvalorizou, entrou as grandes lavouras, daí área pequena não era mais viável. Não tinha nada de produto químico" (E6, 12/07/13, p. 5). A pequena propriedade de agricultura familiar viu-se impossibilitada de continuar produzindo soja, pois o aumento da produtividade com a utilização dos agrotóxicos fortaleceu os grandes produtores, enquanto aqueles possuidores de territórios menores precisaram se adaptar à novas possibilidades, muitas vezes unindo-se em torno de cooperativas para garantir as vendas e suprir as demandas comerciais.

Vale salientar que a utilização de agrotóxicos, que se dá em grande parte a partir da década de 1970, segundo Spadotto (2004), pode-se perceber que este foi beneficiando aqueles produtores que possuíam maior quantia de maquinário para a utilização na propriedade, que estudos atuais mostram que a região Sul é a segunda maior em utilização de agrotóxicos, os quais "[...] são moléculas sintetizadas para afetar determinadas reações bioquímicas de insetos, microrganismos, animais 
e plantas que se quer controlar ou eliminar" (SPADOTTO, 2004, p. 12). As necessidades mercadológicas também foram se alterando com a região do Vale do Taquari, adentrando no sistema internacional econômico, pressionando muitos pequenos produtores a aumentar sua produção ou, então, a trocar de produção.

Referente ao uso de agrotóxicos, como exemplo o pepino, este é um alimento que possui muitas pragas e necessita da utilização de produtos químicos para sua preservação. O entrevistado E22 (22/12/2014) ressalta que, em decorrência das pragas e também devido à pouca mão de obra para acabar com ervas daninhas e arbustos indesejados, em tudo que planta tem que ser utilizado agrotóxico. Segundo o produtor, caso isto não ocorra, ele não colhe nenhum alimento. Entretanto, assim como tantos outros entrevistados, ele menciona que não é questão de opção, mas de sobrevivência, pois, se pudesse, não colocaria agrotóxicos, pois ele tem consciência de que estes produtos trazem uma série de malefícios para os seres humanos e o meio ambiente. ${ }^{12} \mathrm{~A}$ necessidade de utilização de agrotóxicos também se dá pela necessidade, já que o agrotóxico acaba se tornando mais econômico em relação à uma mão de obra.

Também se destaca um aspecto relevante, que predomina na grande parte do território dos municípios de descendência açoriana: o cultivo de acácia e eucaliptos. O produtor E 44 (28/01/2016), Microrregião Centro, informa que, devido à introdução feita por vizinhos, seu pai iniciou o cultivo da acácia, mas acabou optando pelo cultivo do eucalipto, que permanece até os dias atuais. Ele ressalta que a opção pela madeira ocorreu pelo fato de a terra acabar sendo arenosa, tornandose imprópria para a produção de alimentos e criação; portanto, a solução de fato é a plantação de árvores para derrubada.

Sobre as práticas religiosas, a revisão bibliográfica aponta que os açorianos eram católicos assíduos. Faziam procissões em homenagem a santos, como a de Nossa Senhora da Conceição. O entrevistado E5 explica a festividade:

Era uma festa que a gente fazia. Aí, naquele tempo, o pessoal doava um leitão, doavam galinha... [...] Cada um dava um pouco pra... [inaudível]. [...] A gente saía nas casas, assim, nas vizinhança pedindo, com a santinha. Era uma santa grande assim de pano, né?

[...] Daí a gente saía com ela e chegava nas casas, dava e eles beijavam, botavam dentro de casa e depois eles davam uma gorjeta pra gente. Dava uma galinha, dava um porco... (E5, 21/06/2013, p. 3).

Outras tradições religiosas açorianas que permanecem entre seus descendentes são as irmandades e o terno de reis. Sobre a primeira, Graebin (2004) e Silva (2009) apontam para o fato de que as irmandades seriam formas de sobrevivência local, trazendo para os dias atuais maior união entre a comunidade, que organiza a festa

12 Quanto este pensamento, é possível percebê-lo em muitos dos descendentes, não apenas de açorianos, como também alemães e italianos. A consciência do uso dos agrotóxicos pode ser entendida a partir das campanhas de conscientização e maior cobrança das empresas e prefeituras no tocante à segurança no trabalho e também a relação com a alimentação. 
da paróquia de São José de Taquari, onde, aliás, ainda se localiza a igreja de mesmo nome, fundada em 1765, em estilo barroco tardio, juntamente com as primeiras levas de casais açorianos no vale.

O terno de reis, que ainda é praticado, é uma importante "festa religiosa que também cultiva as tradições luso-açorianas. A festa mostra a identidade cultural da cidade através de uma mistura de tradições" (MARQUES, 2012, p. 478). O entrevistado E5 relata como funciona o terno de reis:

Tu presta atenção: é, como eu vou dizer, tem um ditadozinho que é do dia $1^{\circ}$ ao dia 06 , que é o Dia dos Reis. Aí eles saíam, faziam aquela turma, quatro cantadores. E um botador de verso. E um gaiteiro. E aí ia, quantos queriam iam junto, mas quatro cantadores tinha que ter. Um tirava a primeira voz, o outro respondia, não é? O outro respondia o outro verso também assim. Aí era quatro, e o gaiteiro, e o botador de verso. Aí o botador de verso dizia o verso que era pra cantar (E5, 21/06/2013, p. 39).

Em seu formato original, o terno de reis é um momento durante as comemorações natalinas em que pessoas se reuniam para cantar na janela de uma determinada casa na vizinhança. Ainda segundo Marques (2012), temos:

Os Ternos de Reis em Taquari são tradição desde o início da povoação açoriana, em 1764. A introdução deste evento na cidade e em grande parte do Rio Grande, é obra de açorianos que antigamente se reuniam em pequenos grupos, com gaita, violão e violino, às vezes, um surdo e também pandeiro, em visita às casas de amigos e parentes a fim de comemorar o nascimento de Jesus (MARQUES, 2012, p. 479, grifo da autora).

Como vemos, a área territorial denominada Vale do Taquari, passou, no decorrer do processo histórico, por reconfigurações territoriais, como é o caso das fronteiras geográficas do alto e baixo rio Taquari e das atuais microrregiões. No que tange às movimentações e migrações açorianas por este espaço, muito embora em termos territoriais nos ativemos a produtores rurais, descendentes estabelecidos nas microrregiões centro e sul, percebe-se uma continuidade da fronteira cultural açoriana no processo de contato com os demais grupos étnicos que também ocupam o território. Vale salientar que alguns cultivos independentes da introdução de outros produtos e de novas tecnologias, permanecem na memória e em algumas práticas vários daqueles produtos e tecnologias desde o momento da colonização. $\mathrm{O}$ mesmo se refere a gastronomia, crenças religiosas e festividades, aspectos que, com base no estudo de Nordari (2009), sobretudo envolvendo teuto e ítalo brasileiro no Oeste de Santa Catarina, nos possibilita deduzir que, mesmo renegociando a etnicidade e seus elementos culturais, os açorianos souberam muito bem manter sua socioculturalidade na região do Vale do Taquari.

\section{CONSIDERAÇÓES FINAIS}

No processo histórico envolvendo a colonização açoriana no Rio Grande do Sul, sobretudo no Vale do Taquari, percebe-se que espaço, território, natureza e cultura estão imbricados, situação que, com base nos estudos de Correa e Bublitz 
(2006, p. 19) pode ser tomada como "uma interpretação histórica da relação 'homem-natureza' nos séculos XIX e XX”. Corroborando a questão, Martins (2007) considera que a relação homem e natureza tem laços íntimos, já que a natureza, com seus recursos disponíveis, pode alterar formas de cultura na sociedade humana bem como a cultura humana pode alterar aspectos ambientais.

Os resultados a partir dos produtores rurais estudados indicam que a ocupação europeia no Vale do Taquari trouxe novos elementos culturais que prevaleceram na região mediante a reinvenção dos próprios costumes e da reatualização de elementos culturais que fortaleceram o sentimento de pertença, em nível comunitário e estruturaram o desenvolvimento regional a partir de suas relações sociais e comerciais, inclusive em nível interétnico.

Assim como os imigrantes alemães, italianos e seus descendentes - que vieram povoar o vale praticamente a partir da segunda metade do século XIX - os imigrantes açorianos e seus descendentes também perpetuam muitos de seus costumes. $\mathrm{Na}$ pesquisa com os produtores rurais das microrregiões com descendência nos ilhéus, podemos perceber que há uma forte herança cultural, apesar do distanciamento histórico da colonização. Muitos, ao lembrarem de contos de seus pais e avós, nos repassam as informações num sentido de epopeia, já que consideram que o desbravamento desta terra foi algo memorável.

A relação entre espaço, natureza, território e atividades na agricultura e pecuária se fazem presentes tanto na memória como nas práticas agropecuárias e socioculturais dos interlocutores pesquisados. Com base na revisão bibliográfica e pesquisa de campo, é possível observar, em áreas das microrregiões centro e sul do Vale do Taquari, comunidades com descendência açoriana, que preservam traços da arquitetura em construções locais, que têm relações com o meio ambiente semelhantes a seus antepassados, que preservam costumes na gastronomia açoriana, como o mocotó, por exemplo, e, na religiosidade, aponta-se a tradição do terno de reis, realizado entre o Natal e o dia seis de janeiro.

Muitos dos descendentes de açorianos lembram com afabilidade a história vivida por seus antepassados, a trajetória da colonização, bem como as mazelas e decepções pelas quais passaram, o que nos faz perceber as relações, conforme Le Goff (1992), entre a memória e a história. Além disso, vale salientar que os açorianos e seus descendentes souberam se adaptar ou readaptar às práticas para garantir sua sustentabilidade envolvendo a agricultura, pecuária e relações com a natureza; da mesma forma, na reatualização de alimentos, considerando que muitos passam a ser substituídos por outros, devido ao solo e às condições de sobrevivência. Constatamos, portanto, que, mesmo com descontinuidades culturais, o grupo étnico açoriano no Vale do Taquari soube manter vários elementos culturais e reelaborar aqueles que se fizeram necessários. 


\section{REFERÊNCIAS}

AGUIAR, Marcos Daniel Schmidt de, et al. Do desenvolvimento ao desenvolvimento territorial sustentável: os rumos da Região do Vale do Taquari no início do século XXI. Análise, Porto Alegre, v. 20, n.1, p.84-103, jan./jun. 2009.

AHLERT, Lucildo; GEDOZ, Sirlei T. Povoamento e desenvolvimento econômico na regiãodo Vale do Taquari, Rio Grande do Sul - 1822 a 1930. Estudo \& Debate, Lajeado, ano 8, n. 1, 2001, p. 49-91.

BARDEN, Júlia Elisabete; AHLERT, Lucildo. Fluxos migratórios e distribuição interna na evolução da economia do Vale do Taquari no período de 1930-70. Estudo \& Debate, Lajeado, v. 10, n. 2, 2003, p. 7-32.

BARTH, Frederik. Os grupos étnicos e suas fronteiras. In: BARTH, Frederik; LASK, Tomke (org.). O Guru, o iniciador e outras variações antropológicas. Tradução de John Cunha Comerford. Rio de Janeiro: Contracapa, [1969], 2000. p. 25-67.

CALLAI, Helena Copetti. Estudar o lugar para compreender o mundo. In: CASTROGIOVANI, Antônio (org). Ensino de geografia prática e textualizações no cotidiano. Porto Alegre: Mediação, 2000.

CARVALHO, Vera Regina. Da ilha dos Açores à freguesia de Taquari: uma trajetória dos imigrantes açorianos no continente do Rio Grande. Estudo e Debate, Lajeado, v. 9, n.1, semestral, 2002. p.39-57.

CHRISTILLINO, Cristiano Luís. Estranhos em seu próprio chão: o processo de apropriações e expropriações de terras na Província de São Pedro do Rio Grande do Sul (O Vale do Taquari em período de 1840-1889). 2004. 372 f. Dissertação (Mestrado em História da América Latina). Universidade do Vale do Rio dos Sinos (UNISINOS), São Leopoldo, 2004.

CORREA, Sílvio Marcus de Souza; BUBLITZ, Juliana. Terra de promissão; uma introdução à eco-história da colonização do Rio Grande do Sul. Santa Cruz do Sul e Passo Fundo: Edunisc e UPF, 2006.

E5 - Entrevistado 5: depoimento [21 jun. 2013]. Entrevistador: Nicolas Dal Magro da Silva e Evanilson de Moraes. Vale do Taquari/RS: s.e., 2013. Gravação em máquina digital. Entrevista concedida a Nicolas Dal Magro da Silva e Evanilson de Moraes. Projeto Desenvolvimento Econômico e Sociocultural da Região do Vale do Taquari/RS. Lajeado. Univates.

E6 - Entrevistado 6: depoimento [12 jul. 2013]. Entrevistador: Nicolas Dal Magro da Silva e Evanilson de Moraes. Vale do Taquari/RS: s.e., 2013. Gravação em máquina digital. Entrevista concedida a Nicolas Dal Magro da Silva e Evanilson de Moraes. Projeto Desenvolvimento Econômico e Sociocultural da Região do Vale do Taquari/RS. Lajeado. Univates.

E19 - Entrevistado 19: depoimento [25 fev. 2014]. Entrevistador: Evanilson de Moraes e Ana Paula Castoldi. Vale do Taquari/RS: s.e., 2014. Gravação em máquina digital. Entrevista concedida a Evanilson de Moraes e Ana Paula Castoldi. Projeto 
Desenvolvimento Econômico e Sociocultural da Região do Vale do Taquari/RS. Lajeado. Univates.

E22 - Entrevistado 22: depoimento [04 dez. 2014]. Entrevistadoras: Ana Paula Castoldi e Simone Elisa Weber. Vale do Taquari/RS: s.e., 2014. Gravação em máquina digital. Entrevista concedida a Ana Paula Castoldi e Simone Elisa Weber. Projeto Desenvolvimento Econômico e Sociocultural da Região do Vale do Taquari/RS. Lajeado. Univates.

E23 - Entrevistado 23: depoimento [08 dez. 2014]. Entrevistadora: Ana Paula Castoldi e Simone Elisa Weber. Vale do Taquari/RS: s.e., 2014. Gravação em máquina digital. Entrevista concedida a Ana Paula Castoldi e Simone Elisa Weber. Projeto Desenvolvimento Econômico e Sociocultural da Região do Vale do Taquari/RS. Lajeado. Univates.

E44 - Entrevistado 44: depoimento [28 jan. 2016]. Entrevistadora: Ana Paula Castoldi e Júlia Leite Gregory. Vale do Taquari/ RS: s.e., 2016. Gravação em máquina digital. Entrevista concedida a Ana Paula Castoldi e Júlia Leite Gregory. Projeto Desenvolvimento Econômico e Sociocultural da Região do Vale do Taquari/RS. Lajeado. Univates

FALEIRO, Silvana Rossetti. Lendo Memórias: 40 anos de Ensino Superior no Vale do Taquari e a construção do regional. Lajeado: Ed. da Univates, 2009.

FERRARI, Maristela. As noções de fronteira em Geografia. Revista Perspectiva Geográfica. Unioeste, v. 9, n. 10, 2014. p.1-25. Disponível em: <http:/ / e-revista. unioeste.br/index.php/pgeografica/article/view/10161/7550> Acesso em: 14 jun. 2016.

FORTES, João Borges. Os casais açorianos: presença lusa na formação do Rio Grande do Sul. Porto Alegre: Martins Livreiro, 1978.

GRAEBIM, Cleusa Maria. “Gentes das Ilhas” dos Açores no Rio Grande de São Pedro (século XVIII): mobilidade, cotidiano e trabalho. In: SCOT'T, Ana Sílvia Volpi; BERTUTE, Gabriel Santos; MATOS, Paulo Teodoro de (orgs). Gentes das Ilhas. Trajetórias transatlânticas dos Açores ao Rio Grande de São Pedro entre as décadas de 1740 a 1790. São Leopoldo: Oikos, 2014, p.164-191.

GRAEBIM, Cleusa Maria. Sonhos, desilusões e formas provisórias de existência: os Açorianos no Rio Grande de São Pedro. 2004. 324 f. Tese (Doutorado em História) - Universidade do Vale do Rio dos Sinos. Centro de Ciências Humanas. Programa de PósGraduação em História. São Leopoldo. 2004

. Vida cotidiana dos açorianos pelas freguesias e caminhos. In: BOEIRA, Nelson; GOLIN, Tau (coord geral). História Geral do Rio Grande do Sul. Colônia. Passo Fundo: Méritos, 2006, v. 1, p. 203-223.

JUNG, Flávio Nirceu. Paverama: fatores de sua emancipação. 2001.116 f. Monografia (Especialização em História) - Universidade de Santa Cruz do Sul. Santa Cruz do Sul, 2001. 
KARAM, Elaine Maria Consoli. Raízes da Colonização: em destaque a Colônia Guaporé e o município de Dois Lajeados. Porto Alegre: CORAG, 1992.

KÜHN, Fábio. Gente da fronteira: sociedade e família no sul da América portuguesa - século XVIII. In: GRIJÓ, Luís Alberto. KUHN, Fábio. GUAZZELI, César Augusto (Coord.) Capítulos de história do Rio Grande do Sul. Porto Alegre: Editora da UFRGS, 2004. p. 47-75.

LASK, Tomke. Apresentação. In: BARTH, Frederik; LASK, Tomke (org.). O Guru, o iniciador e outras variações antropológicas. Tradução de John Cunha Comerford. Rio de Janeiro: Contracapa, [1969], 2000.p.7-23.

LE GOFF, Jacques. História e memória. 2. ed. São Paulo: UNICAMP, 1992.

MARQUES, Marli Pereira. Terno de Reis: um sinal cultural açoriano em Taquari. In.: FERNANDES, Evandro; NEUMANN, Rosane Márcia; WEBER, Roswithia (org.). Imigração: diálogos e novas abordagens. São Leopoldo: Oikos, 2012. p. 478-482.

MENEZES, Avelino de Freitas. Os açorianos na estruturação do Brasil do Sul: as levas de meados do século XVIII. In.: Scott; Ana Silvia Volpi; BERUTE, Gabriel Santos; MATOS, Paulo Teodoro de (org.). Gentes das ilhas: Trajetórias transatlânticas dos Açores ao Rio Grande de São Pedro entre as décadas de 1740 a 1790. São Leopoldo: Oikos, 2014. p. 60-81.

MESQUITA, Zilá. Procura-se o coração dos limites. In: LEHNE, Carlos; CASTELO, Iara Regina; SCHÄFFER, Neiva Otero (org.). Fronteiras no Mercosul. Porto Alegre: UFRGS, Edições Prefeitura Municipal de Uruguaiana, 1994, p.69-73.

NODARI, Eunice Sueli. Etnicidades renegociadas: Práticas socioculturais no Oeste de Santa Catarina. Florianópolis: Editora da UFSC, 2009.

PESAVENTO, Sandra Jatahy. História do Rio Grande do Sul. 6. ed. Porto Alegre: Mercado Aberto, 1992.

SANTOS, Milton. Por uma Geografia Nova. São Paulo: Ed. Hucitec, 1996.

SCOTT, Ana Sílvia Volpi; BERUTE, Gabriel Santos. “Gentes das Ilhas”: repensando a migração do Arquipélago dos Açores para a Capitania do Rio Grande de São Pedro no século XVIII. In: SCOTT, Ana Sílvia Volpi; BERTUTE, Gabriel Santos; MATOS, Paulo Teodoro de (orgs). Gentes das ilhas. Trajetórias transatlânticas dos Açores ao Rio Grande de São Pedro entre as décadas de 1740 a 1790. São Leopoldo: Oikos, 2014, p.105146.

SILVA, Cleidirose. Cultura açoriana em Taquari e Paverama: costumes e religiosidade preservados ao longo do tempo. 2009. 150 p. Monografia (Graduação). Curso de História, Centro Universitário Univates: Lajeado, 2009.

SILVA, Jorge Junqueira. Diferentes formas de associativismo em duas Comunidades Rurais geograficamente próximas, no Vale do Taquari, RS. 2006, 52 f. Monografia. Universidade Estadual do Rio Grande do Sul - Unidade Encantado/RS. Curso de Desenvolvimento Rural e Gestão Agroindustrial. Encantado. 2006. 
SPADOTTO, Claudio A. Monitoramento do risco de agrotóxicos: princípios e recomendações. Jaguariúna: Embrapa Meio Ambiente, 2004.

VEDOY, Moisés Ilair Blum. Contatos interétnicos: sesmeiros, fazendeiros, imigrantes alemães e indígenas Kaingang em territórios das bacias hidrográficas do Taquari-Antas e Caí. 2015. 100 f. Monografia (Graduação) - Curso de História, Centro Universitário UNIVATES, Lajeado, 2015.

WIEDERSPAHN, Henrique Oscar. A colonização açoriana no Rio Grande do Sul. Porto Alegre: EST/Instituto Cultural Português, 1979. 